\title{
Article
}

\section{Estimation of Tree Density in the Juniper Forest of North-East Iran by ALOS Data}

\author{
Hadi Fadaei*1, Tetsuro Sakai*1, Tetsuhiko Yoshimura*2 and Moriya Kazuyuki*1
}

\begin{abstract}
High resolution satellite images of forests have a key role to play in natural resource management. We describe and evaluate a new analysis technique for, 1- Identification of the juniper's tree crown 2- Estimating juniper forest density by counting trees per hectare, 3- Estimating vegetation indices. In this paper, we introduce a new means of analysis for counting trees, calculation of the vegetation index (VI) and comparison with tree numbers per hectare. Results showed linear regression models between the normalized difference vegetation index (NDVI), the soil adjusted vegetation index (SAVI), the optimized soil-adjusted vegetation index (OSAVI) and number of trees per hectare $R^{2}=0.79,0.79,0.87, C V \%=19.22,19.27,19.22$ respectively. In addition, the linear regression of counting trees with the new analysis technique by TreeVaW software and trees measured by ALOS data (Avnir-2 and Prism) $R^{2}=0.72$ will be demonstrated. In this study, we have found a useful tool for counting trees in arid and semi-arid regions, thus enabling estimation of biomass and better decision making for natural resource managers in fields of environmental benefit.
\end{abstract}

Keywords: tree density, Juniperus polycarpus, NDVI, SAVI, OSAVI

\section{INTRODUCTION}

Juniperus polycarpus is a subspecies $J$. excelsa, which Iranians know as the Persian juniper located in the northeast of Iran. This forest is evergreen or populated by conifers, which is a widespread low-density forest. This species grows within an elevation range of 1,500 meters and 2,000 meters above sea level and belongs to the biggest vegetation zone of five zones in Iran called Irano-Touranian, an area of about 3,452,775 ha. Forests in arid and semi-arid areas are typically scattered with small trees. In recent years, most field studies of forests have concentrated on forest change by using satellite imagery over a period of time, providing mapped results of forest changes seen using Landsat imagery and vegetation cover by Moderate Resolution Imaging Spectrometer (MODIS) data. In recent studies of the arid and semi-arid forest in Iran, tree density has been estimated by forest fieldwork employing various methods, most recently by combining sampling plot and line methods as an inventory method (Transect-Plot) based on the Universal Transverse Mercator (UTM) grid with an admissible relative error $20 \%$. For this process, topographical maps with adequate scale were initially prepared, and then the topographical maps were matched with the UTM grid. An inventory of a specified area of the topographical map was made, gathering data by means of forest fieldwork using a combination of sampling plot and line (Transect-Plot). Before carrying out a total inventory, a primary sampling plot and line (Transect-Plot) inventory must be carried out. A relative error of less than $20 \%$ in the primary sampling plot and line (Transect-Plot) must be achieved, in order for data to be used in a final inventory. Juniperus polycarpus is most important in these regions for its environmental effect especially in relation to biomass. For this reason, this species and estimation of its population per hectare must be identified. In recent years in these regions, an inventory of trees has been pursued by time-consuming and expensive fieldwork
Corresponding author: Hadi Fadaei

E-mail: fadaei@bre.soc.i.kyoto-u.ac.jp

${ }^{* 1}$ Department of Social Informatics, Graduate School of Informatics, Kyoto University, Kyoto 606-8501 Japan
${ }^{* 2}$ Educations and Research Center for Biological Resources, Faculty of Life and Environmental Science, Shimane University, Matsue, Shimane 690-8504 Japan 
(transport, helpers, tools, measurement devices), then forest data collection with a sampling relative error of $20 \%$ or less is needed. In this study, we hypothesize that counting trees by our new analysis technique using TreeVaW software (which has been used to estimate forest tree density at a relatively low cost and with little time consumption), can be a useful tool for counting trees in arid and semi-arid regions. In this study, our first objective is (i) using Advanced Land Observing Satellite (ALOS) data (Avnir-2 and Prism) to identify the juniper tree, (ii) estimation of tree density by new analysis technique for counting trees per hectare, (iii) comparing new analysis techniques using TreeVaW (Tree Variable Window) software and trees measured in the ALOS imagery, and (iv) estimation of vegetation indices. The inventory obtained useful information such as estimation of the canopy cover and major estimators containing the number of trees in the forest of Juniperus polycarpus, reducing costs and time taken (particularly significant in arid and semi-arid environments).

Although essential resources for millions of rural people in fewer developing countries, these forests are unchecked and under-inventoried, leading to poor predications of future trends in these forests. There is, therefore, a clear need for better inventory data generated by relatively low cost inventory techniques (GAUTAM et al., 2004; FAO, 2006). In developed countries, inventories are still obtained by mapping forest stands and their content by the interpretation of medium scale aerial photographs backed by field assessments and plot measurements and accomplished by expensive and time-consuming endeavors (GougEON et al., 2006). Open forests have special features that provide excellent opportunities for remote sensing-based forest inventory. When a strong relationship exists between forest attributes and the features extracted from remote sensing (RS), these forest attributes can be estimated in a cost-effective way from RS imagery using regression, modelling techniques (OzDEMIR, 2008). A new analysis technique and advances in remote sensing would help obtain detailed measurements useful for sustainable forestry. The combination of new technology for remote sensing and new techniques for data analysis are likely to narrow the gap between users' needs and producers' products. OzDEMIR (2008) has found a strong relationship between field-measured stem volume and tree attributes, including tree crown area and tree shadow area in a sparse Crimean juniper (Juniperus excelsa M. BiEB.) forest in southwestern Turkey. Despite recent technological progress in remote sensing applicability and accuracy, little is known about vegetation properties of arid and semi-arid lands other than just the normalized difference vegetation index (NDVI) reflection of the vegetation or soil moisture. In other words, most studies examine the reflection of averaged areas containing trees rather than trees individually. Though the NDVI is a good index of general vegetation properties, it does not provide insights about possible demographic trends in tree populations such as number of individuals, ageing, mortality, spacing, etc (MousTAKAs et al., 2009). MOUSTAKAS et al. (2009) has found a strong relation- ship between the number of trees and the canopy area $\left(\mathrm{m}^{2}\right)$. A review of some other research reveals various methods employed for delineation of trees using high-resolution imagery. Local minimum filtering; developed the local minimum (L-Min) filtering to detect the darkest pixel with a low value between two neighboring crowns, and utilized the forest area only after discriminating the forest and non-forest using automated or semi-automated classification techniques in a preprocessing step (Gougeon, 1995). The local maximum algorithm (LM) method presented is primarily low-level image processing to segment significant tree crown using image smoothing (BLAZQUEZ, 1989). The purpose of this technique is to round off the contour of each individual tree crown and merge different contour parts that are close to each other, and then applying an edge detection step for a continuous tree crown. Other techniques used are convex curvature and primal sketching of images to discern an individual tree crown. Tree identification and delineation algorithm (TIDA); this method was presented as part of research undertaken as a component of a Ph.D. program at the University of Melbourne (Culvenor, 2002). This algorithm is based on several criteria; 1- Identification of local maxima throughout the image, 2- Identification of local minima throughout the image, $3-$ Clustering of crown pixels. Template matching-based; this method was introduced and includes a model generation and template-matching (Pollock, 1996). A series of models are built to characterize what a tree looks like at different locations in an image by taking into consideration both a tree's geometric and radiometric properties. Segment boundaries and treetop locations, This algorithm can be divided into two stages. The first stage utilizes an edgedetection method to obtain initial tree-crown boundaries. The second stage can be separated into two main parts: treetop marker selection and marker-controlled watershed segmentation introduced (WANG et al., 2004). Watershed segmentation; VINCENT and SOLUE (1991) introduced this algorithm. With a simple definition, watershed lines are the divide lines of the domains of attraction of drops of water or that splits an image into areas, based on the topology of the image, also we can express process of partitioning a digital image into multiple segments (sets of pixels). Intuitively, for application to image analysis, the watershed lines represent the location of pixels which best separate the dark objects (regional minima), in terms of grey level difference (contrast). High-pass filtering, (WALSWORTH et al., 1999) tried to delineate the tree crowns using a high-pass filter. To isolate the crown apex, properties of the original image were enhanced. To locate the crown boundary, an inverted image was generated by substituting the pixel with the lowest value by 255 and the pixel with the highest value by 0 . The resultant image enhanced by filtering depends on the image spatial resolution and the window size too. The pixel size of the image must be smaller than the average crown diameter. Valley-following algorithm; developed this algorithm (GOUGEON, 1995), used for isolation of individual crowns in Canadian boreal forests. The method finds crown 
boundaries by first following the shaded areas (radiometric valleys between trees, and then refining the boundaries using a rule-based program. KATOH et al. (2009) investigate conifer plantation management in Japan using high-resolution airborne data based on an individual tree crown (ITC) approach. They have found errors between the ITC approach using the valley-following method and the field-survey data ranging from 0.3 to $30.2 \%$. This error depended on tree crown size, density, and other factors. GougEON et al. (2006) investigated ITCs; they used high-resolution panchromatic and multispectral bands Ikonos and applied two algorithms for his research. They found overall accuracy was 67 percent. YANG et al. (2007) studied on vegetation index for two experiment fields, they recorded $\mathrm{Hy}$ perspectral reflectance $(350 \sim 2,500 \mathrm{~nm})$ data at two different sites of rice in two experimental fields and then applied twenty-five vegetation indices (VIs). The results showed that green waveband normalized difference vegetation index (NDVIgreen) and transformed chlorophyll absorption in reflectance index (TCARI) / optimized soil-adjusted vegetation index (OSAVI) had the best predictive powers for LAI. FAN et al. (2009) estimated the relationship between NDVI and LAI in semi-arid grassland in Inner Mongolia using in-situ measurements. They developed a general linear and general exponential relationship

$$
\begin{aligned}
& L A I=0.0897+1.424 \operatorname{NDVI}(R=0.79), \\
& L A I=0.128 \exp (N D V I / 0.311)(R=0.77),
\end{aligned}
$$

which can be used for various grazing intensity grasslands and for higher vegetation covered areas (e.g. wetland) in the region.

The aim of this study was (i) Identification of the juniper's tree crown, (ii) Estimation of density of juniper forests by counting trees per hectare, and (iii) Estimation of vegetation indices. Subsequently, to determine simple linear relationships between counting trees and vegetation indices, and introducing a new analysis technique for areas of open forest in the arid and semi-arid regions especially juniper forests in the Irano-Touranian region of Iran using ALOS imagery.

\section{MATERIAL AND METHODS}

The Study Area

Juniperus polycarpus is a subspecies $J$. excelsa, which is known as Persian Juniper in Iran, mostly located in the northeast of Iran between latitude $36^{\circ} 86^{\prime} 03^{\prime \prime}$ and $37^{\circ} 47^{\prime} 06^{\prime \prime}$ and between longitude $58^{\circ} 39^{\prime} 00^{\prime \prime}$ and $59^{\circ} 17^{\prime} 06^{\prime \prime}$ (Fig. 1). This forest has coniferous evergreen trees, which have a low density. This species grow at an elevation range of 1,500 up to 2,500 meters above sea level; belonged to the biggest vegetation zone of five zones in Iran called the Irano-Touranian zone consisting of an area of about 3,452,775 ha. The study area selected for this research has a pure Juniper species, typically $3-4 \mathrm{~m}$ tall, with a $3-5 \mathrm{~m}$ crown diameter and the space between each tree being above 3 meters approximately. A 1,600-hectare $(3,900 \times 3,900$ m) area incorporating 12 sampling plots of 9 ha each $(300 \times 300$ m) was selected for this research (Fig. 2).

The Image Data

The ALOS imagery was used; this satellite was launched on 24 January 2006 by Japan. ALOS image data acquired on 25 October 2007 was used for the analysis. ALOS uses the Advanced Visible and Near Infrared Radiometer type two (AVNIR-2) sensor, which is a multispectral band. This sensor contains of four bands, band1 [blue, $0.42-0.50 \mu \mathrm{m}$ ], band2 [green, $0.52-0.60 \mu \mathrm{m}$ ], band3 [red, $0.61-0.69 \mu \mathrm{m}$ ] and band4

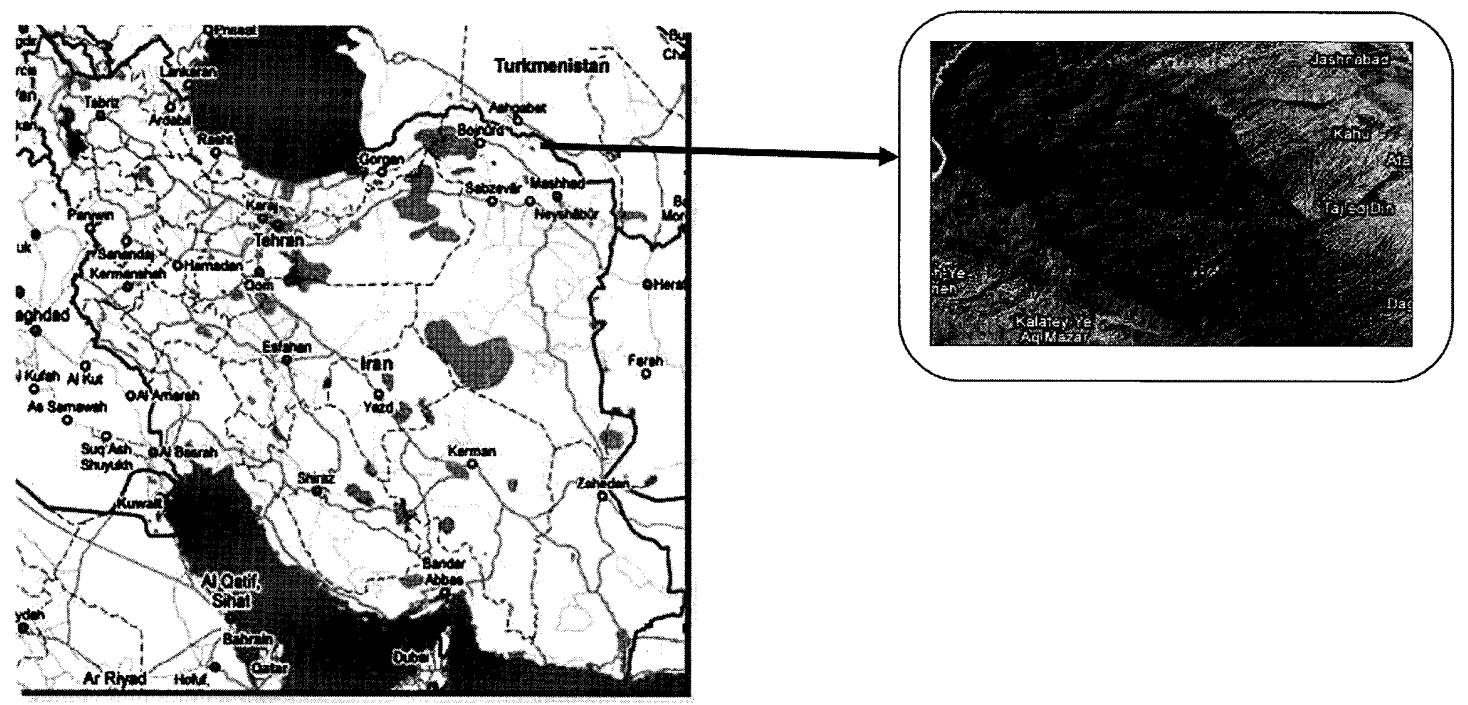

Fig. 1 The study area 


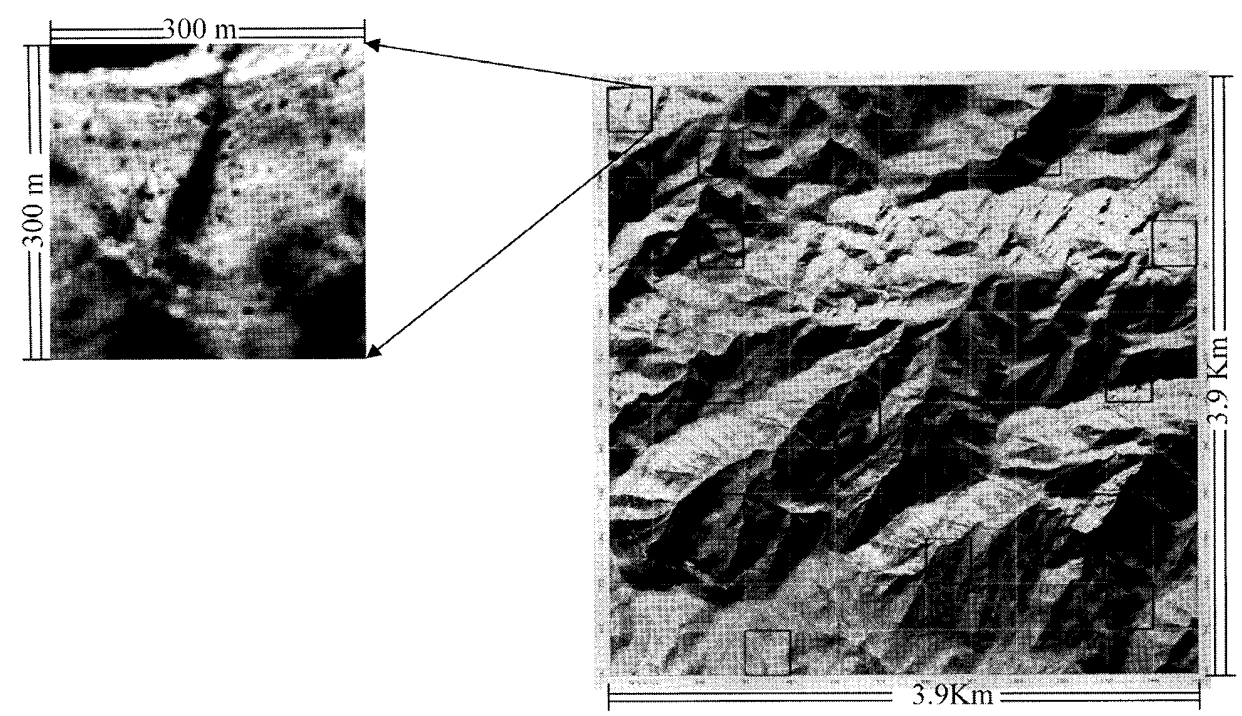

Fig. 2 Position of sample plots

[near infrared, $0.76-0.89 \mu \mathrm{m}$ ] respectively. The spatial resolution is $10 \mathrm{~m}$ at the nadir. In addition, ALOS uses the Panchromatic Remote-Sensing Instrument for Stereo Mapping (PRISM) consisting of these optics; 1- forward, 2- backward 3- nadir. They consist of one band with wavelength $0.52-0.77 \mu \mathrm{m}$ and spatial resolution is $2.5 \mathrm{~m}$ at the nadir, and swath width $70 \mathrm{~km}$ at the nadir and $35 \mathrm{~km}$ at the triplet mode. The field of view is $+/-1.5 \mathrm{deg}$ and Quantization (image processing) that can observe the surface of the earth is 8 Bit.

Algorithm Details: Method of Estimating the Tree Density

Estimation of tree density is the key in estimating forest volume. High-resolution imagery (PRISM and Avnir-2) has been used for this method. Image sharpening tools were used to automatically merge a low-resolution color, multi- spectral image using a high-resolution gray scale image (with resampling to the high-resolution pixel size) sharpening technique that uses a mathematical combination of the color image and high resolution data (BhatnaGar et al., 2009). Our algorithm's design was based on the treetop approach. Delineation and identification of Juniper trees (conifers), a regular circular/ellipsoi$\mathrm{dal} /$ cone-shape is exhibited with a separation tree. Juniper trees are assumed as cone-shaped and the cone apex has a maximum value. Pixels around maximum value have a minimum value denoting the crown of the tree's diameter. TreeVaW software was designed for Lidar data using the treetop algorithm. The results of the local maxima (LM) filtering on the IKONOS data are promising for individual tree identification (Wulder et al., 2004). TreeVaW is an extension of IDL that allows for the extraction of forest stand data using Local Max filtering and variable windows. TreeVaW is a very useful program because it is almost completely automated and it gives foresters the ability to easily analyze large areas of forest

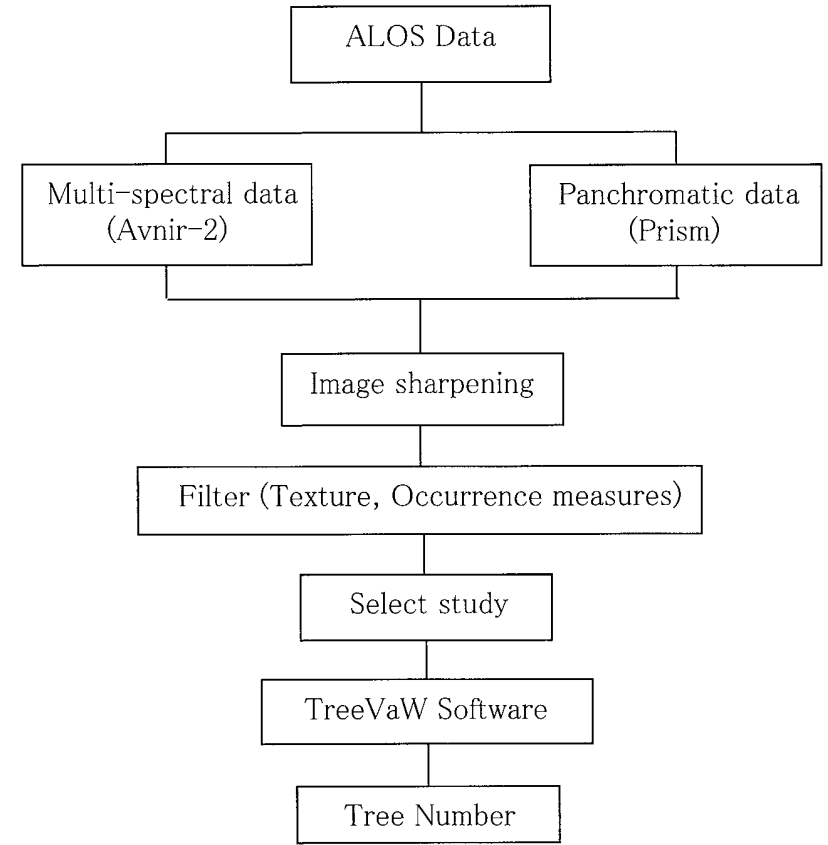

Fig. 3 Diagram of the procedures used for counting tree

remotely. My new analysis technique for counting trees, based on the treetop algorithm, is based on software designed with an LM filter window $3 \times 3$ for identification of trees (See Systematic of my new analysis technique is in Fig. 3).

\section{Calculation of Vegetation Indices}

\section{Explanation of indices}

The index used in this study is a ratio-based index called NDVI. 


$$
N D V I=\frac{N I R-R E D}{N I R+R E D}
$$

where $N I R=$ near infrared band, $R E D=$ red band. Original equation of soil adjusted vegetation index (SAVI) is

$$
S A V I=\left[\frac{N I R-R E D}{N I R+R E D+L}\right](1+L) .
$$

$L=0.5$ in Eq. (4) is optimal adjustment at soil influences.

$$
S A V I=1.5 \frac{N I R-R E D}{N I R+R E D+0.5} .
$$

OSAVI is

$$
O S A V I=\frac{N I R-R E D}{N I R+R E D+0.16},
$$

$L=0.16$

Have been used fusion of images from AVNIR-2 and Prism data, and in fact have used a multispectral band with 2.5 meters resolution to calculate vegetation index (it is necessary to have near infrared and red bands). Since vegetation is green, it absorbs solar energy to form wavelengths of visible light reflectance energy in near infrared. Vegetation indices are variable and relate to the estimation of biomass (RAvi et al., 2008). Subsequently, correlation coefficient linear regressions between vegetation indices and number of trees counted have been calculated from each plot (9 ha).

Data Analysis

Vegetation indices' values have been calculated from a sample plot ( 9 ha, 14,400 data results equal to the number of total pixels). Subsequently, maximum filtering $(3 \times 3)$ of the 14,400 data results was calculated. Results of maximum filtering $(3 \times 3)$ have achieved 1,600 data results. Subsequently, the frequency of data between ranges of vegetation indices was calculated. Co-

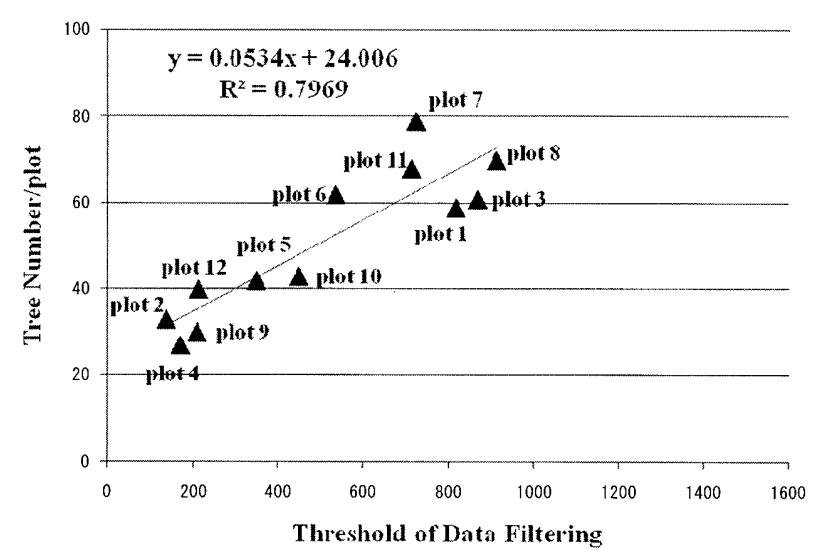

Fig. 4 The relationship between NDVI $(0.1216-0.1533)$ and number of Tree $C V \%=19.22$ efficients of linear regression were calculated from results of tree numbers and threshold of filtering data from vegetation indices in the sample plot ( 9 ha). The computer software used in this study was ENVI, Microsoft Excel, and TreeVaW software.

\section{RESULTS AND DISCUSSION}

From A 1,600-hectare $(3,900 \times 3,900 \mathrm{~m})$ area 12 sampling plots of 9 ha each $(300 \times 300 \mathrm{~m})$ was selected that have been calculated relationship between vegetation indices and counting tree. Also for accuracy of TreeVaW, has been calculated relationship between numbers of trees measured from image sharpening and number of trees by TreeVaW software. Results of all the experiments such as NDVI, OSAVI, SAVI and accuracy of TreeVaW are showed in Figs. 4, 5, 6 and 7 respectively, and their assessments including $R$ and $C V \%$. The high $R$-values of regression models indicate the good relationships between Threshold of data filtering OSAVI and number of tree per hectare. OSAVI is a good index for predicting LAI (YANG et al., 2007). This result of this research accordance with result of

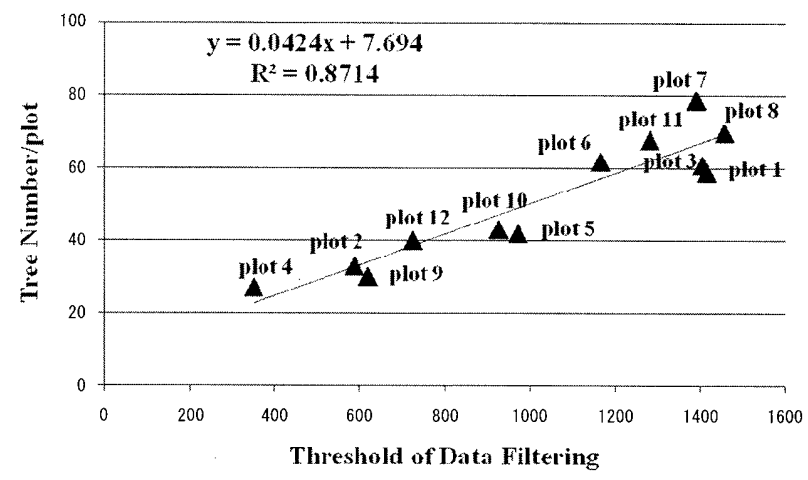

Fig. 5 The relationship between OSAVI (0.1133-0.2008) and number of Tree $\mathrm{CV} \%=19.22$

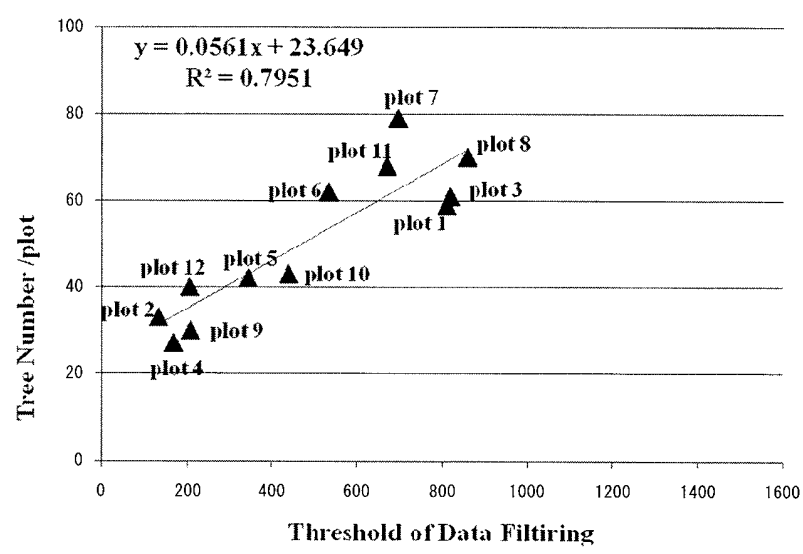

Fig. 6 The relationship between SAVI $(0.1965-0.245)$ and number of Tree, CV\% $=19.27$ 


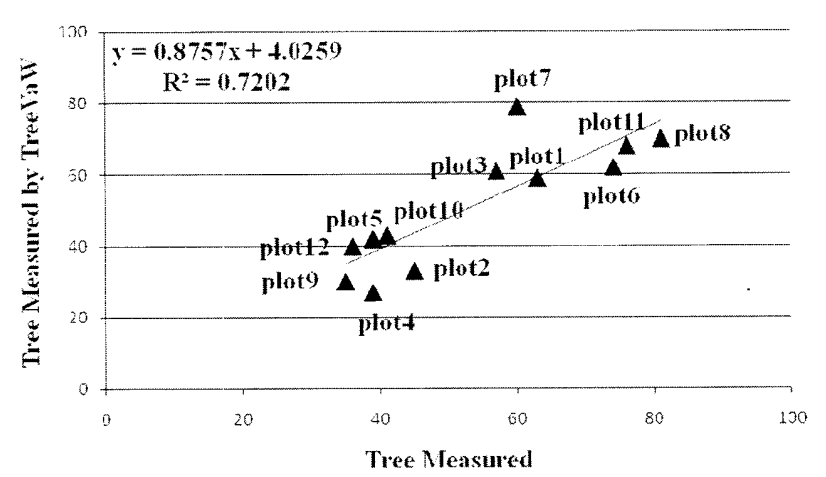

Fig.7 The relationship between numbers of tree measured and number of tree by TreeVaW software

Estimation of vegetation biophysical parameters by remote sensing using radial basis function neural network was investigated (YANG et al., 2007).

This study was divided into two sections, 1- influences of vegetation indices 2 - new analysis technique for counting trees in arid and semi-arid forests. The former is calculated by some ratio between the red (used for photosynthesis, low reflectance from green vegetation) and near infrared (NIR) (high reflectance from green vegetation) wavelengths, while the latter is based on the perpendicular distance to a soil line in two or more band space. The indices used in this study are a ratio-based index called NDVI, SAVI and OSAVI. There is a relationship of positive correlation between vegetation cover and vegetation indices, but this discussion focuses on influences of vegetation indices to distinguish between vegetation. These vegetation indices can be influenced by several non-vegetation factors, such as soil-background, dead biomass and atmospheric conditions (but the latter have mostly been corrected for) (DRISS et al., 2004). There are influences of vegetation indices in the non-vegetation, such as soil background and dry plant material and woody plant (tree). In this study, OSAVI correlated more strongly than SAVI and NDVI (see Figs. 4, 5 and 6). Soil background is a possible factor that was introduced by (HUETE 1988) which adjusting for the slope and origin of the soil-line, the SAVI is the NDVI with the origin shifted by $L$ (= $\left.\left.l_{1}, l_{2}\right):\left(\left(N I R+l_{1}\right)-\left(\operatorname{Red}+l_{2}\right)\right) /\left(N I R+l_{1}\right)+\left(\operatorname{Red}+l_{2}\right)\right)$. The optimal choice of $\mathrm{L}$ depends on the vegetation cover, but OSAVI had high ability for distinguishing non-vegetation factors.

In relation to the accuracy of estimating tree numbers in sparsely forested arid and semi-arid regions, using TreeVaW software was effective (see Fig. 7). There is clearly a need for further study on this topic. In addition, some of the methods may need to be changed so that the results are closer to the field data. I hope by employing this method might provide a useful tool for counting trees in arid and semi-arid regions. Moreover, our new analysis technique of counting tree density will be useful for enabling better decision making for natural resource managers in fields of environmental benefit.

\section{CONCLUSIONS}

In the present work, vegetation indices on based of LM filter window $3 \times 3$ for data filtering was estimated. It will be needed to obtain optimum size of filtering window for vegetation indices in the arid and semi-arid forest. Thresholds or parameters can also be considered as scale modifications when linked directly to object size or indirectly to size through an image property that is size related (DoNALD et al., 2005). In future work it need to investigate the relationship between vegetation indices and Juniper trees usage two size algorithms of maximum filtering $(3 \times 3)$ and $(5 \times 5)$ in the sample plots.

\section{ACKNOWLEDGEMENTS}

This work was supported by Kyoto University, Department of Social Informatics, and laboratory of Biosphere Informatics. We are grateful of Mr. F. OGusHI from ITT visual Information Solutions K.K Agency for technical advisor. We are very grateful to Mr. J. HARRIS for revision of the final English text.

\section{LITERATURE CITED}

Bhatnagar, G. and Balasubramanian, R., (2009): A new image fusion technique based on directive contrast. Electronic Letters on Computer Vision and Image Analysis 8(2): 18-38

BlAZQUEZ, C. H., (1989): Computer-based image analysis and tree counting with aerial color infrared photography. J. Imag. Technol. 15: 163-168

Culvenor, D. S., (2002): TIDA: an algorithm for the delineation of tree crowns in high spatial resolution remotely sensed imagery. Computers \& Geosciences 28: 33-44

Donald, G. L., Francois, A. G., Sally, T., Trisalyn, N., Charles, N. B. and Dennis, P., (2005): Automated tree recognition in old growth conifer stands with high resolution digital imagery. Remote Sens. Environ. 94: 311-326

FAN, L., GAO, Y., BRÜCK, H. and BERNHOFER, Ch., (2009): Investigating the relationship between NDVI and LAI in semiarid grassland in Inner Mongolia using in-situ measurements. Theor. Appl. Climatol. 95: 151-156

FAO, (2006): Global forest resources assessment 2005: progress towards sustainable forest management. Forestry Paper 147. Food and Agriculture Organization of the United Nations, Rome, 320pp

Gautam, A. P., Shivakoti, G. P. and WebB, E. L., (2004): Forest covers change, physiography, local economy, and institutions in a mountain watershed in Nepal. Environ. Manage. 33: 48-61

Gougeon, F. A., (1995): A crown-following approach to the automatic delineation of individual tree crowns in high spatial resolution aerial images. Can. J. Remote Sens. 21(3): 274-284

Gougeon, F. A. and Donald, G. L., (2006): The individual tree 
crown approach applied to Ikonos images of a coniferous plantation area. PE\&RS 72: 1287-1297

HuEte, A. R., (1988): A soil-adjusted vegetation index (SAVI). J. Remote Sens. Environ. 25: 295-309

Katoh, M., Gougeon F. A. and Leckie D. G., (2009): Application of high resolution airborne data using individual tree crowns in Japanese conifer plantations J. For. Res. 14: 10-19

Moustakas, A. and Hristopulos, D. T., (2009): Estimating tree abundance from remotely sensed imagery in semi-arid and arid environments: bringing small trees to the light. Stoch Environ. Res. Risk Assess. 23: 111-118

OzDEMIR, I., (2008): Estimating stem volume by tree crown area and tree shadow area extracted from pan-sharpened Quickbird imagery in open Crimean juniper forests. Int. J. Remote Sens. 29: 5643-5655

POLLOCK, R. J., (1996): The automatic recognition of individual trees in aerial images of forests based on a synthetic tree crown image model. $\mathrm{PhD}$ thesis, Computer Science, The University of British Colombia, Vancouver, Canada, 172pp

Sripada, R. P., Schmidt, J. P., Dellinger, A. E. and BeEgle, D. B., (2008): Evaluating multiple indices from a canopy reflectance sensor to estimate corn $\mathrm{N}$ requirements. Agronomy
Journal 100(6): 1553-1561

VIncent, L. and SollLe, P., (1991): Watersheds in digital spaces: An efficient algorithm based on immersion simulations. IEEE Transactions on Pattern Analysis and Machine Intelligence 13(6): $583-598$

WALSWORTH, N. A. and KING, D. J., (1999): Image modeling of forest changes associated with acid mine drainage. Computers \& Geosciences 25(5): 567-580

WANG, L., Gong, P. and Gregory S. B., (2004): Individual tree-crown delineation and treetop detection in high-spatialresolution aerial imagery. PE\&RS 70: 351-357

Wulder, M. A. and White, J. C., (2004): Comparison of airborne and satellite high spatial resolution data for the identification of individual trees with local maxima filtering Int. J. Remote Sens. 25: 2225-2232

YANG, X., Huang, J., Wang, J., WANG, X. and LiU, Z., (2007): Estimation of vegetation biophysical parameters by remote sensing using radial basis function neural network. Journal of Zhejiang University Science A 8(6): 883-895

(Received 23 September 2009) (Accepted 10 March 2010) 